\title{
Reflexos da lógica organizacional na identidade profissional: variações do discurso autobiográfico
}

\author{
António Calha \\ Instituto Politécnico de Portalegre, Portalegre, Portugal
}

\section{Resumo}

O objetivo deste artigo é analisar a forma como a identidade profissional incorpora os princípios das lógicas de gestão organizacional que enquadram a trajetória profissional dos indivíduos. A análise incide nas referências identitárias mobilizadas na produção do relato autobiográfico e que estruturam a identidade profissional. Para tal, são apresentados os resultados obtidos a partir da análise de um corpus documental de 100 autobiografias que integram relatos das experiências profissionais. Os resultados revelaram que a diferente configuração das trajetórias profissionais, estruturados em torno de uma maior ou menor vinculação a conteúdos funcionais estritos, corresponde a uma atribuição de significados também distintos à ideia de experiência profissional, com implicações na identidade profissional e no modo como esses indivíduos se apresentam narrativamente.

Palavras-chave: self, identidade profissional, autobiografia, trabalho, discurso

Abstract: Reflections of organizational logic in professional identity: variations of the autobiographical discourse The objective of this article is to analyze how the professional identity embodies the principles of the organizational management logic that frame the professional career of individuals. The analysis focuses on the identity references mobilized in the autobiographical narrative production and that structure professional identity. For this purpose, the results obtained from the analysis of a documentary corpus of 100 autobiographies are presented. The results revealed that the different configuration of the professional trajectories, structured around a greater or lesser attachment to the strict functional content, also corresponds to an assignment of meanings that are also different from the idea of professional experience, with implications for the professional identity and the way these individuals present themselves in the narrative.

Keywords: self, professional identity, autobiography, work, discourse

Resumen: Reflejos de la lógica organizacional en la identidad profesional: variaciones del discurso autobiográfico En este artículo se analiza cómo la identidad profesional incorpora los principios de la lógica de la gestión organizacional que engloban la trayectoria profesional. El análisis se centra en las referencias de identidad movilizadas en la producción del relato autobiográfico y que estructuran la identidad profesional. Con este fin, se presentan los resultados del análisis de un corpus documental de 100 autobiografías que integran relatos de experiencias profesionales. Los resultados mostraron que las diferentes configuraciones de las trayectorias profesionales, estructuradas en torno a un mayor o menor apego a contenidos funcionales estrictos, corresponden también, a una asignación de diferentes significados con relación a la idea y experiencia profesional, con implicaciones para la identidad profesional y la forma cómo estos individuos se presentan narrativamente.

Palabras clave: self, identidad profesional, autobiografía, trabajo, discurso

\footnotetext{
${ }^{1}$ Endereço para correspondência: Avenida de Santo António, 7300, Portalegre, Portugal.E-mail: antoniocalha@hotmail.com
} 
As transformações ocorridas nos últimos anos, na esfera do trabalho, envolvem não só alterações à sua configuração, mas estendem-se ao seu significado para os indivíduos. A configuração do trabalho regular a tempo inteiro e por tempo indeterminado, que prevaleceu nos países ocidentais durante décadas, é hoje substituída por novas formas de relações de trabalho. Esta transformação é acompanhada por uma alteração da estabilidade e da previsibilidade das trajetórias profissionais. Sob a égide dos princípios da polivalência e da flexibilidade, os trabalhadores são cada vez mais solicitados a um compromisso e a uma maior entrega à atividade profissional. As alterações ocorridas têm, necessariamente, impacto nos fundamentos da identidade profissional e obrigam, consequentemente, a um ajustamento da orientação profissional. Como demonstra Watson (2008), existe um crescente número de evidências empíricas sobre a importância do trabalho realizado pelos indivíduos para a construção da sua identidade e com repercussões nas suas práticas laborais.

Neste artigo, procura encontrar-se, no discurso autobiográfico dos indivíduos, reflexos das grandes transformações sociais e organizacionais que ocorreram na esfera laboral ao longo das últimas décadas. Pretende-se perceber se há ou não variações nas representações sociais das trajetórias profissionais em indivíduos com experiências profissionais marcadas pela maior ou menor estandardização das atribuições funcionais, a que correspondem as duas lógicas organizacionais identificadas por Watson (2005): uma lógica "sistêmico-controladora" e uma lógica "processual-relacional".

De acordo com o trabalho desse autor, as lógicas de gestão organizacional podem ser enquadradas em duas abordagens discursivas predominantes. De um lado, a abordagem sistêmico-controladora que incorpora uma visão mecânica do trabalho gerencial, com forte ênfase na racionalização, no controle e no conhecimento técnico. De outro lado, a abordagem processual-relacional, onde os modelos rígidos de organização dão lugar a modelos de natureza mais flexível. Nessa abordagem, alternativa à ortodoxia sistêmico-controladora, a gestão empresarial orienta-se pelos princípios da criatividade, da reatividade e da flexibilidade, num claro contraponto aos princípios burocráticos que marcaram anteriormente as práticas de gestão.

Com a crescente hegemonia da lógica processual-relacional sobre a lógica sistêmico-controladora, os conceitos de autonomia e de liberdade começam a fazer parte do léxico das práticas de gestão e o desenvolvimento pessoal torna-se uma dimensão da nova gestão empresarial. A competência dos indivíduos passa a incluir a sua capacidade de mobilidade e de ajustamento a novos desafios profissionais. Longe de permanecer vinculado a uma profissão ou a uma qualificação, a aferição do valor do trabalhador faz-se com base na sua capacidade de adaptação, que lhe possibilite a transição e a maleabilidade a situações de diferente natureza, e na sua polivalência, que lhe permita a mudança de atividade ou de ferramentas de trabalho, segundo a natureza da relação que estabelece com os outros ou com os objetos.

As alterações ocorridas na lógica de gestão organizacional apontadas por Watson (2005) têm repercussões nos sujeitos que participam da organização. Ao moldarem os processos de interação organizacional e os modos de reconhecimento institucional, as lógicas de gestão condicionam a forma como as identidades profissionais se constroem no interior das instituições. Ao nível académico, a maior pluralidade e menor normatividade das trajetórias de trabalho obrigaram a uma revisão e ampliação das conceções de carreira. Na sistematização das produções narrativas acadêmicas sobre as construções das carreiras, realizada por Ribeiro (2013), são identificados dois extremos coexistentes: (a) de um lado, o extremo tradicional sobredeterminado por padrões mais tradicionais baseado no social, estável e fechado nos seus próprios modelos; (b) de outro lado, o extremo flexível baseado na pessoa, disperso nas redes sociais, gerador de mudanças e marcado pela abertura a novos modelos de construção para as carreiras.

As alterações que se vêm registando no mundo do trabalho no sentido da flexibilização, complexificação e heterogeneização das atividades faz sobressair um discurso que exalta a subjetividade e que, ao nível das práticas de gestão, se traduz numa maior responsabilização individual no trabalho, na individualização das remunerações, das carreiras, da formação, da informação/comunicação e na avaliação das potencialidades pessoais (Kovács, 2006). Ao enfatizar a realização do indivíduo através da sua criatividade e do seu empenho nos diferentes projetos em que se envolve, afirma-se o poder, a capacidade e a liberdade que os indivíduos detêm para moldarem as suas vidas. Nesta nova realidade entre os "fragmentos" identitários que sustentam as imagens de si encontram-se conceitos, expressões e declarações que compõem a cultura organizacional. O modo como os sujeitos exprimem e caracterizam, discursivamente, a sua relação com o papel profissional resulta de uma configuração de significados construídos pelos indivíduos e pela cultura em que se inserem. É através desse sistema dinâmico de significados que os indivíduos atribuem sentido aos acontecimentos de vida. Dessa forma, a aplicação dos modelos gerenciais emergentes necessita de ser acompanhada por ajustamentos à orientação profissional e à incorporação de 
novos modelos e conceitos, como o de adaptabilidade de carreira (Ambiel, 2014). A inserção profissional não obedece, hoje, exclusivamente a uma lógica única derivada da racionalidade económica (Dubar, 2001), mas estende-se a outras lógicas socialmente construídas e compartilhadas.

Nesse contexto, e como preconizam as propostas socioconstrucionistas, as narrativas autobiográficas, produzidas por trabalhadores em seus processos singulares de construção das carreiras, constituem uma das formas privilegiadas de compreensão das carreiras na contemporaneidade (Ribeiro, 2013). Nessa linha se enquadram os recentes trabalhos de Savickas (2012), onde se demostra a importância da utilização das pequenas histórias biográficas como fonte de construção das carreiras. Também o trabalho de LaPointe (2010) concetualiza a identidade de carreira como uma prática de articulação e negociação de posições identitárias na narração das experiências profissionais. Não se trata de tomar o discurso individual de forma isolada, mas antes colocar no eixo de análise a relação entre os indivíduos e o contexto. Como salienta LaPointe (2010) ao considerar a posição dos indivíduos a sua abordagem situa as identidades em contextos históricos, culturais e internacionais particulares ao invés de se limitar a olhar para a construção da carreira como um constructo individual. Com base nas abordagens narrativas, Meijers e Lengelle (2012) propõem um modelo de transformação através da escrita, como forma de realçar as aprendizagens que se vão processando à medida que se narram estórias de carreira.

Todas estas abordagens têm em comum a noção de narrativa como meio de construção de significações sociais. Como salienta Ribeiro (2013), as narrativas da experiência profissional são baseadas nos discursos sociais disponíveis, sendo construídas e legitimadas nas relações psicossociais. A narrativa medeia entre o self e o mundo social (Bruner, 2003), é na dinâmica das interações das vivências pessoais que o self se constrói, modifica e se reconstrói. Esse self narrativo sustenta-se na autoria da história do sujeito, desenvolvida ao longo do tempo com base em histórias e memórias pessoais. Esta visão discursiva do self enquadra-se naquilo a que Macedo e Silveira (2012) designam de teorias que localizam o self em um espaço interno individual separado por fronteiras permeáveis do mundo exterior.

As transformações ocorridas nos últimos anos no mundo do trabalho, a crescente pluralidade das trajetórias profissionais e a perda de normatividade alteram os focos identitários que sustentam o self. Nesse sentido, como nota Dubar (2006) as formas anteriores de identificação e colagem a papéis profissionais estabelecidos (típicas da lógica sistêmico-controladora) tornam-se problemáticas.
As identidades "tayloriana", "de ofício", "de classe", vão sendo desvalorizadas à medida que se afirma a ideia de um indivíduo racional e autónomo, implícita no discurso da gestão empresarial a partir da década de noventa do século XX (Boltanski \& Chiapello, 2002). A identidade "de empresa" traduzida em carreiras internas e reguladas desestrutura-se e assiste-se a uma ampliação dos espaços de construção de referenciais identitários, simultaneamente mais fragmentados.

Conceber a identidade como sendo estática e inalterável torna-se um erro face às mudanças vivenciadas pelos indivíduos ao longo da sua trajectória profissional. É nesse sentido que Dubar (2006) alude a diferentes modos de identificação que coexistem nas sociedades contemporâneas, entre as quais se inclui a identidade narrativa que se constrói no próprio ato de se contar. Trata-se de um $\mathrm{Si}$ narrativo que cada um tem necessidade de ver reconhecido numa procura de autenticidade. Como refere Dubar (2006), é a continuação de um Eu projetado nas pertenças sucessivas, perturbado pelas mudanças exteriores, abalado pelas vicissitudes da existência.

No âmbito da orientação profissional, Savickas (2004) realça a importância do self na identificação e diferenciação dos papéis profissionais. Esta dimensão do self profissional (Silva, Taveira \& Ribeiro, 2011) torna possível aos indivíduos produzir, com base na autorreflexão, um significado sobre a sua carreira, a partir do qual orientam o seu comportamento. Nos últimos anos, diferentes autores (Savickas, 2005; Stebleton, 2010) vêm alertando para o potencial das abordagens narrativas nos processos de orientação profissional, em particular na forma como favorecem o acesso ao universo de referências identitárias dos indivíduos e ao modo subjetivo como perspetivam a sua carreira. $\mathrm{O}$ recurso à narrativa autobiográfica no processo de aconselhamento permite perceber as escolhas individuais e os princípios que guiaram essas escolhas. Como refere Savickas (2005), as estórias sobre a carreira dizem-nos como o self de ontem se tornou o self de hoje e se tornará no self de amanhã.

Neste contexto, parece mostrar-se pertinente o propósito deste trabalho: perceber como os indivíduos descrevem a sua experiência profissional e como interpretam e incorporam os discursos que enquadram os diferentes contextos organizacionais. Para tal, recorre-se à análise dos modos de apresentação de si na narrativa autobiográfica, procurando identificar a forma como esses indivíduos estruturam a sua identidade profissional com base na incorporação da lógica organizacional onde se desenrola a sua atividade profissional. Conhecer a forma como a experiência profissional molda a conceção que os indivíduos têm da sua carreira e de si, enquanto trabalhadores, 
constitui uma dimensão importante da orientação profissional e pode contribuir para potenciar o sucesso profissional (Forrier, Sels, \& Stynen, 2009). Como referem Lima e Coimbra (2004), o contexto social da orientação profissional permite ao sujeito tornar inteligível a sua conceção do self e modificar as narrativas sobre o self.

\section{Método}

No sentido de aprofundar o conhecimento acerca dos processos de apresentação narrativa da identidade profissional e o modo como são influenciados pelas características particulares dos contextos profissionais em que estiveram/estão inseridos, procedeu-se à análise de um conjunto de autobiografias elaboradas no âmbito do sistema de reconhecimento, validação e certificação de competências (RVCC). O processo RVCC constitui uma oferta do sistema educativo português destinada a adultos que demonstrem abrangência de experiências (pessoais, profissionais e sociais), as quais indiciem um conjunto diversificado de competências, apresentem expectativas orientadas para a obtenção de qualificação escolar e revelem prevalência de motivações extrínsecas (Almeida et al., 2008). O processo baseia-se na elaboração de informação documental com recursos ao "balanço de competências" e à "abordagem autobiográfica". É através da descrição narrativa do percurso de vida que os candidatos evidenciam as aprendizagens que realizaram ao longo da vida e as competências que delas decorreram no sentido da obtenção de equivalência a um certo nível de ensino. Trata-se, portanto, de um processo eminentemente individual de autoanálise sobre a experiência de vida de onde decorre uma autoavaliação sobre o processo de aprendizagem nos diferentes contextos de vida. Os candidatos são convidados a apresentar a sua história de vida e a narrar a sua experiência e sua relação com o mundo. Desse trabalho resulta invariavelmente a descrição do trajeto profissional que, em muitas situações, construi a dimensão basilar em que se sustenta a apresentação narrativa de si.

Nos últimos anos tem surgido algum interesse pelo valor analítico da narrativa autobiográfica produzida no âmbito do processo RVCC decorrendo do acesso que proporciona à reflexividade e aos quadros de referência dos indivíduos (Abrantes, 2013; Dionísio, Castro, \& Silva, 2013). Tendo em conta os objetivos da investigação e o potencial analítico destes documentos procedeu-se à recolha e análise de um corpus documental de 100 autobiografias elaboradas por adultos que passaram pelo sistema de reconhecimento, validação e certificação de competências (RVCC), entre 2006 e 2012, em Portugal, tendo sido dada especial atenção aos relatos e descrições das experiências profissionais destes indivíduos. Apesar de não ter existido a preocupação de constituir uma amostra estatisticamente representativa de autobiografias procurou-se, ainda assim, diversificar a amostra, ajustando-a ao perfil sociodemográfico dos candidatos certificados no sistema RVCC. O material autobiográfico recolhido é extenso e marcado, numa primeira leitura, pela singularidade de cada relato de vida, no entanto, após o trabalho de exploração e análise de conteúdo revelaram-se pontos de saturação das narrativas relativamente às categorias de análise consideradas.

$\mathrm{Na}$ análise procurou seguir-se os protocolos qualitativos e intensivos de uma pesquisa baseada na narrativa autobiográfica. Esta estratégia metodológica possibilitou o acesso à pluralidade de discursos dos sujeitos e permitiu, simultaneamente, estabelecer a ligação entre os discursos narrativos e os contextos que estruturam as suas trajetórias profissionais. O material autobiográfico recolhido foi compilado e trabalhado de modo a sujeitá-lo aos procedimentos de análise de conteúdo seguindo a lógica inerente à análise qualitativa (Guerra, 2008), com o propósito de interpretar e reconstruir o sentido da narrativa. Subjaz ao trabalho analítico a ideia de que os conteúdos narrativos indiciam conteúdos culturais latentes que são mediados pelas estruturas sociais e simbólicas que contextualizam a sua produção (Ruquoy, 1997). Em última instância, a nossa análise foi conduzida com a intenção de proceder à inferência de conhecimentos relativos às condições de produção (Bardin, 2009).

Inicialmente procedeu-se à definição de categorias de análise e à elaboração de uma grelha analítica; posteriormente identificou-se, nos documentos autobiográficos, as unidades de registo categorizáveis e análogas entre si. As unidades de registo identificadas foram, sobretudo, de natureza semântica (baseadas numa escolha resultante do sentido temático) e linguística (destacando-se, a este nível, as palavras-chave) (Ghiglione \& Matalon, 2001). Durante a análise procurou-se identificar elementos nas narrativas autobiográficas que possibilitassem objetivar o tipo de lógica organizacional que emerge das descrições da experiência profissional. Desse modo foram constituídas duas categorias de análise com vista à caracterização da lógica organizacional onde se desenrola a atividade profissional. A primeira categoria, respeitante à lógica sistêmico-controladora, foi subdividida em várias subcategorias que incluíam: menções a regras de conduta; alusões a processos rígidos de tomada de decisão; descrições herméticas do conteúdo funcional; referências a aspetos reguladores e disciplinadores relacionados com normas formais da organização; manifestações de lealdade aos deveres oficiais e referências a uma ideia de carreira profissional. A segunda categoria, respeitante à lógica processual-relacional, 
integrou as seguintes subcategorias: menções a princípios de ação; alusões a processos flexíveis de tomada de decisão; descrições do conteúdo funcional pouco rígidas e definidas; referências a aspetos reguladores baseados em formas de diálogo institucionalizado e a meios informais; manifestações de lealdade à missão da organização e referências à noção de projetos profissionais.

Todo o corpus analítico foi classificado com base nos critérios seguidos na análise de conteúdo (Bardin, 2009): a exaustividade (abrangendo a totalidade do material recolhido), a exclusividade (evitando classificar um mesmo elemento do conteúdo em duas categorias diferentes) e a pertinência (procurando classificar os trechos em função dos objetivos da análise). Cada autobiografia foi trabalhada individualmente, tendo sido criada uma tabela a partir da qual se procedeu à comparação dos dados recolhidos e ao aprimoramento das categorias de análise por forma a garantir a sua homogeneidade. Num momento subsequente procedeu-se à classificação das autobiografias em uma das duas lógicas organizacionais, tendo-se utilizado como critério de classificação a predominância do tipo de referências no discurso autobiográfico.

$\mathrm{Na}$ Tabela 1 é apresentada a caracterização sociodemográfica dos autores do material autobiográfico que constitui o corpus documental e o seu enquadramento em cada uma das lógicas organizacionais consideradas na análise.

Tabela 1

Perfil Sociodemográfico dos Autores do Material Autobiográfico e respetivo enquadramento na lógica sistêmico-controladora e na lógica processual-relacional

\begin{tabular}{lccc}
\hline \multicolumn{1}{c}{ Características da amostra } & $\mathrm{n}$ & $\begin{array}{c}\text { Lógica } \\
\text { sistêmico-controladora }\end{array}$ & $\begin{array}{c}\text { Lógica } \\
\text { processual-relacional }\end{array}$ \\
\hline Sexo & 45 & 22 & 23 \\
$\quad$ Masculino & 55 & 24 & 31 \\
Feminino & & & \\
Grupo etário & 5 & 5 & 0 \\
$>$ 64 anos & 10 & 8 & 2 \\
entre 55 e 64 anos & 35 & 15 & 16 \\
entre 45 e 54 anos & 30 & 14 & 14 \\
entre 35 e 44 anos & 18 & 4 & 2 \\
entre 25 e 34 anos & 2 & 0 & 15 \\
$<25$ anos & & & 34 \\
Habilitações literárias & 31 & 16 & 5 \\
$1^{\circ}$ ciclo (4 anos de educação formal) & 60 & 26 & \\
$2^{\circ}$ ciclo (6 anos de educação formal) & 9 & 4 & 41 \\
$3^{\circ}$ ciclo (9 anos de educação formal) & & & 13 \\
Situação profissional & 81 & 40 & 0 \\
Empregado & 16 & 3 & \\
Desempregado & 3 & 3 & \\
Aposentado & & & \\
\hline
\end{tabular}

Refira-se que o estudo cumpriu os princípios éticos que orientam a investigação científica. No processo de recolha do material autobiográfico os participantes foram devidamente informados dos objetivos da investigação e acederam voluntariamente a participar no estudo. Foi, igualmente, garantido e respeitado o anonimato de todos os participantes, desse modo os nomes utilizados na identificação dos excertos transcritos neste estudo são fictícios.

\section{Resultados e Discussão}

Nas narrativas autobiográficas analisadas evidenciam-se claras diferenças nos modos de produção da imagem de si na descrição da experiência profissional, que derivam de distintas configurações da trajetória profissional. A forma como os indivíduos se descrevem na narrativa autobiográfica varia de forma contrastante entre a construção de uma imagem de si como protagonista de um 
sistema institucional e a imagem de realização fluida de si. A primeira está presente, sobretudo, na narrativa dos indivíduos com trajetórias profissionais enquadradas institucionalmente em organizações burocráticas, que obedecem a uma lógica sistêmico-controladora, e caracteriza-se por uma forte identificação com papéis profissionais estandardizados. A segunda caracteriza, sobretudo, as narrativas de indivíduos que ocupam funções associadas a formas menos estandardizadas de desempenho dos papéis profissionais, marcados pela flexibilidade e polivalência e onde sobressai uma lógica de natureza processual-relacional.

No relato da experiência profissional dos sujeitos protagonistas do modelo sistêmico-controlador a apresentação de si-mesmo é delimitada por um conjunto coerente de normas e valores. A identidade profissional construída por estes sujeitos, que se insinua implicitamente na narrativa, alicerça-se na interiorização de papéis sociais organizados, estáveis e prescritos normativamente. Encontramos semelhanças com aquilo a que Dubar (2006) designa de forma de "identidade estatutária": inseparável da dominação burocrática, sistemática, aquela que muitas vezes esmaga o indivíduo através do peso das regras anônimas e muitas vezes cegas, que subordina os dirigidos aos dirigentes. Nas autobiografias analisadas, dos casos que se enquadram neste modelo de apresentação de si sobressaem três dimensões no seu discurso.

Em primeiro lugar, apresentam-se como protagonistas de um papel prescrito institucionalmente, assumindo as características típicas do trabalhador burocrata enquadrado numa organização de trabalho amplamente vertical que apela ao cumprimento estrito de regras abstratas e ao não envolvimento dos trabalhadores na delineação de métodos e de objetivos de produção. O relato seguinte, de um trabalhador dos serviços administrativos de uma escola, é particularmente ilustrativo:

Ao ingressar na carreira administrativa, onde fundamentalmente uma boa preparação teórica/prática é fundamental tenho sempre procurado a forma de me enquadrar nas transformações muito acentuadas que se têm implementado ao longo destes anos. [...] Ao chefe de serviços compete participar no conselho administrativo e, na dependência da direcção executiva da escola, coordenar toda a actividade administrativa nas áreas da gestão de recursos humanos, da gestão financeira, patrimonial e de aquisições e da gestão do expediente e arquivo. (Damião, 52 anos, chefe de serviços administrativos)

No discurso de Damião estão latentes os atributos éticos do bom burocrata: adesão estrita aos procedimentos, respeito pela hierarquia e compromisso com a finalidade do cargo (du Gay, 2005). A narrativa destes indivíduos gravita em torno do ethos do cargo burocrático, a identidade profissional é vinculada à descrição pormenorizada de práticas profissionais realizadas no âmbito do respeito escrupuloso por uma ética específica: "as normas padrão às quais estamos sujeitos", nas palavras de Damião. $\mathrm{O}$ apego às normas previstas nos códigos constitui o exemplo típico da imagem identitária que se procura projetar na narrativa. São frequentes as referências simbólicas a uma identidade institucionalizada, orientada pelo interesse do serviço público e formatada por códigos e regulamentos. Na narrativa destes sujeitos, a apresentação de si é formatada pelo tipo de trabalhos que exerceram, com funções bem definidas por normas, trata-se de um discurso onde onde sobressai a competência técnica para o exercício de funções que requerem conhecimentos normativos e legais específicos.

A obediência e a disciplina constituem uma segunda dimensão importante do discurso destes indivíduos, enunciadas como uma virtude moral. Como refere Bauman, o ideal burocrático da disciplina "aponta para a total identificação com a organização - que, por sua vez, só pode significar disposição de obliterar a própria identidade separada e sacrificar os próprios interesses" (Bauman, 1998). Um bom exemplo de transmissão da ideia de obediência a princípios éticos que sobrepõem o interesse comum aos interesses pessoais está presente no discurso de Berta:

Tento ser honesta, recta, leal e justa demonstrando toda a integridade do meu carácter, escolhendo sempre quando estiver diante de duas opções a melhor e a mais vantajosa para o bem comum. Ter consciência que o meu trabalho é regido por princípios éticos tento ser cortês, respeitadora da hierarquia, ser responsável e determinada. (Berta, 54 anos, secretária)

Uma terceira dimensão do discurso relaciona-se com a forma como fazem a retrospetiva da trajetória profissional enquanto carreira. A estabilidade e a regularidade das progressões profissionais incutem linearidade à narrativa e a expressão de uma racionalidade instrumental no planeamento antecipado e a longo prazo da carreira. Baltazar traça uma descrição da sua trajetória profissional assente no enquadramento legal pormenorizado, especificando as datas mais marcantes desse percurso:

Em [...], fui promovido a Escriturário-dactilografo, depois de ter efectuado o concurso para esta categoria em [...]. Comecei esta nova carreira sendo colocado no sector de caça e pesca. Em [...], concorro ao 
concurso de habilitação destinado a Escriturários/ dactilógrafos. Em [...], por despacho do Senhor Director Regional, transito para a categoria de Terceiro-oficial, onde continuei a executar as tarefas no sector da caça e pesca. Pela Lei $n^{\circ}$ 12-A/2008 de 2008.02.27, que estabelece os regimes de vinculação, de carreiras e de remunerações dos trabalhadores que exercem funções públicas, transitei para a Carreira de Assistente Técnico. (Baltazar, 52 anos, assistente técnico)

Como se observa nos excertos selecionados, a apresentação de si destes indivíduos aproxima-se de uma lógica de pertença a categorias profissionais, legitimadoras do tipo de relações sociais que caracterizam o modelo burocrático e se inscreve na lógica sistêmico-controladora. A noção que têm de competência, e que se subentende nas descrições que fazem do trabalho e da experiência vivida no contexto laboral, aproxima-se de uma conceção burocrática da sua qualificação profissional, que se afasta dos modelos gerenciais emergentes. A narrativa vincula-se, assim, a categorias estatutárias a que correspondem papéis predefinidos (Dubar, 2006) e balizada entre os seus deveres e direitos. Os deveres assumem um forte pendor normativo associado às responsabilidades funcionais e a processos de subordinação hierárquica. Por sua vez, os direitos correspondem a uma estabilidade e segurança do trabalho, assim como à perspetiva de progressão profissional, mais ou menos automática, pela antiguidade.

O modo de apresentação de si na narrativa dos sujeitos com trajetórias profissionais marcadas pela lógica processual-relacional assume uma configuração diferente dos casos apresentados anteriormente. $\mathrm{O}$ seu discurso rompe com as delimitações impostas pela rigidez do modelo de especialização burocrática e dos sistemas normativos de classificação profissional. À descrição pormenorizada de atribuições funcionais estandardizadas, presentes nos modos de apresentação de si sob influência da lógica sistêmico-controladora, contrapõe-se a emergência das noções de mobilidade, agilidade e flexibilidade. A narrativa destes sujeitos acompanha as alterações ideológicas que caracterizam a nova gestão empresarial e que correspondem, por um lado, à deslegitimação da hierarquia e da autoridade formal, bem como das carreiras profissionais no decurso da vida e, por outro lado, à afirmação de critérios relacionados com a personalidade e as relações pessoais (Boltanski \& Chiapello, 2002). A narrativa incorpora as ideias de autonomia e de polivalência, centrando-se não apenas nas responsabilidades funcionais, mas também em competências indispensáveis para a realização da sua atividade profissional. Estes relatos estão próximos da forma identitária narrativa descrita por Dubar (2006). Não se trata apenas de uma construção discursiva, ela implica uma definição de si ancorada naquilo que se faz. Esta identidade narrativa é uma construção, pelos sujeitos, de um agenciamento das suas experiencias significantes, mas menos normativas e mais plurais quando comparadas com as apresentadas anteriormente. Como esclarece Dubar (2006) trata-se de uma forma identitária que se sustenta na valorização das competências pessoais, da responsabilidade individual e da empregabilidade de cada um. Esta forma virada para a realização de si coloca os indivíduos na obrigação de afirmar a incerteza e a precariedade dando-lhe um sentido. O excerto do discurso de Cesário elucida bem a incorporação de elementos relacionados com o modelo da nova gestão empresarial que apela à polivalência e ao comprometimento do trabalhador com o processo produtivo da empresa:

Passado dois anos fui convidado para polivalente, aceitei de imediato o cargo e comecei a estudar pressões, temperaturas, stocks, planos de produção, mapas de competências, tudo ligado ao mundo da indústria automóvel, era uma empresa com uma política de qualidade muito exigente, o tema era: "Fazer bem à primeira e exceder as espectativas do cliente" (Cesário, 32 anos, operário de multinacional do sector automóvel)

Em alguns casos a instabilidade profissional e existência de múltiplas experiências profissionais dificultam a atribuição de linearidade à trajetória profissional, a ideia de carreira é, nestes casos, substituída pela noção de experiência em diferentes projetos profissionais. Cada projeto, sendo diferente e novo, é apresentado como uma oportunidade de aprendizagem e de enriquecimento de competências. A ideia de empregabilidade constitui uma noção chave na apresentação de si na narrativa da trajetória profissional. Ela é a prova da aquisição de competências em diferentes experiências profissionais. Trata-se de competências apresentadas na narrativa como sendo parte do capital pessoal e mobilizáveis em diferentes contextos. Desta forma, a referência à aquisição de competências é mais frequente na narrativa destes sujeitos, quando comparados com aqueles que apresentam trajetórias profissionais estáveis, assumindo centralidade no seu discurso:

A primeira obra em que trabalhei para a supracitada empresa foi a via rápida entre [...] e [...]. Foi nessa obra que aprendi a manobrar máquinas pesadas; pás mecânicas, retroescavadoras, bulldozers, gruas, cilindros estáticos e pneumáticos. Tive a oportunidade 
de trabalhar numa série de máquinas que me permitiram adquirir uma série de competências a qual penso ter dado bom uso. (Diogo, 39 anos, operário de empresa de construção)

$\mathrm{O}$ discurso destes indivíduos incorpora argumentos contemplados nos discursos contemporâneos da reforma organizacional relacionados, em particular, com as ideias de autonomia e flexibilidade, em contraposição com a rigidez funcional dos indivíduos cujas narrativas foram anteriormente analisadas. Os valores associados a essa imagem idealizada de trabalhador competente, tendem a reportar-se a três ideias distintas, ainda que associadas: (a) as competências de adaptabilidade, criatividade e iniciativa; (b) a capacidade de liderança e de trabalho em equipe e (c) o relacionamento interpessoal e, em particular, a capacidade para a mediação e resolução de conflitos.

No que respeita às competências de adaptabilidade, iniciativa e criatividade, salienta-se a capacidade de agir em diferentes contextos profissionais, de modo informado e crítico, e aberto à iniciativa. Estas competências associadas à vida profissional têm uma particular repercussão na narrativa autobiográfica dos indivíduos com percursos menos estáveis ou marcados pela flexibilidade profissional:

Considero-me também muito persistente, ou seja, enquanto não consigo os meus objectivos, não deixo de fazer o que pretendo. Também aprecio quando as coisas que faço ficam bem feitas, pois assim é mais fácil atingir o meu objectivo, que éter sucesso na minha vida. Gosto de mostrar iniciativa nas coisas que me são pedidas e gosto de utilizar a minha criatividade nas funções que desempenho. (Marco, 31 anos, desempregado com trajetória profissional instável na área da construção e indústria)

A aptidão cognitiva para resolver problemas surge como o corolário interior indispensável para a realização de papéis profissionais menos definidos. Esta dimensão do discurso de apresentação de si é aquela que evidencia maiores pontos de contraste relativamente aos indivíduos com percursos mais estáveis e regulares. As características éticas do funcionário burocrata, que constituem a motivação para o cumprimento de funções mais estandardizadas, diverge das capacidades de adaptabilidade, criatividade e iniciativa necessárias à resolução de problemas. A narrativa é, assim, pontuada pela descrição de episódios onde a intervenção dos indivíduos se revela fundamental na superação de ocorrências inesperadas:
Estava a trabalhar no turno das 24:00 às 08:00 da manhã, com o gerador de vapor também chamados caldeiras [...]. Numa noite tive um problema, faltou-me a água na alimentação da caldeira e sem água esta não pode trabalhar, afinal se não entra água, não sai vapor. A bomba do furo que estava a abastecer a caldeira avariou. Então, como não estava ninguém da manutenção, só chegavam as 08:00 da manhã, tive que resolver o problema. Fui buscar uma mangueira, liguei-a a uma torneira do furo e comecei a alimentar a caldeira. Se não tivesse tido essa ideia, a produção teria estado parada até as 08:00 da ma$n h a ̃$. (Ismael, 40 anos, operário do sector corticeiro)

A descrição destes episódios é particularmente frequente nos casos em que a ocupação profissional se inscreve em trabalhos de natureza industrial. A cadeia de produção constitui, nestes casos, o palco privilegiado de enquadramento dos exemplos narrados, seja sob a forma de descrições que retratam o engenho de soluções simples que evitam a interrupção do processo produtivo, seja em situações, mais complexas, em que o sujeito tem a iniciativa de propor alterações ao processo produtivo:

Uma das ideias que coloquei em prática e com autorização das chefias foi a mudança rápida de P/ number, ou seja, mudar rapidamente as máquinas para outro tamanho de peças e foi feito da seguinte maneira: os tabuleiros rolantes tinham diversos parafusos de medidas diferentes, para mudar de P/ number (tamanho) era preciso uma caixa de ferramenta completa para usar nesses parafusos, eu tirei todos eles e pedi para ser colocados parafusos e respectivas roscas todos da mesma medida, e com esta alteração, o trabalho de mudança deixou de ser feito em 60 minutos e passou para 15 minutos bastava uma chave em vez de 15 ou 20 e os operadores não estavam tanto tempo parados e a produção aumentou. (Manuel, 52 anos, desempregado com trajetória profissional na industria automóvel e aeronáutica)

A salvaguarda da cadência produtiva, ou o aumento de produção, evidenciam-se, de forma transversal, como o critério de pertinência na evidenciação de competências de adaptabilidade, criatividade e iniciativa. As capacidades de trabalho em equipe e de liderança constituem uma segunda dimensão da imagem idealizada do trabalhador competente contemplada no discurso destes indivíduos. Estas competências contrastam com o estatuto profissional de subordinado, que caracteriza a situação da maioria dos indivíduos e que, num olhar distanciado, parece pouco 
propício à aquisição de tais competências. Neste contexto, o discurso tende a ser omisso na descrição de episódios concretos da trajetória profissional e orienta-se para considerações gerais sobre a importância das competências em causa:

Enquanto trabalhador sempre trabalhei bem em equipe, pois penso que um bom profissional tenta retirar ideias e discute-as, evita abordar questões pessoais no trabalho em equipe e considera apenas propostas concretas. Tenta ter um diálogo competente, onde os argumentos devem ser apresentados de maneira clara, para que possam ser entendidos e discutidos entre todos. Um membro em equipe deve saber lidar com conflitos e saber administrá-los com firmeza e habilidade. Os conflitos acabam sempre acontecendo e isso é saudável, desde que se saiba tirar deles melhor proveito para o sucesso da negociação. Conflitos não significam desavenças, mas diferentes pontos de vista. (Ismael, 40 anos, operário do sector têxtil)

Ainda assim, encontramos referências esporádicas a situações que pressupõem o domínio de capacidades de liderança:

Ao chegar a [...], arranjei logo emprego na empresa de construção civil [...] onde já era pedreiro, e já tinha alguma responsabilidade. Tinha a meu cargo alguns serventes, que tinha que orientar no local de trabalho e dar-lhes a fazer alguns serviços. (Jorge, 35 anos, operário da construção civil)

As competências relacionadas com o relacionamento interpessoal e a resolução de conflitos valorizam qualidades particulares insuficientemente consideradas nas formas típicas de qualificação de natureza burocrática. São destacadas competências mobilizáveis em diferentes situações profissionais e relacionadas com o saber-estar e o relacionamento interpessoal. Tratam-se de competências valorizadas como importantes critérios de integração laboral amplamente divulgados por diferentes dispositivos de inserção profissional (Boltanski \& Chiapello, 2002), entre os quais se incluem o saber apresentar-se, estabelecer laços ou resolver conflitos. O exemplo seguinte é ilustrativo:

Obviamente que quando se trabalha com pessoas podem surgir alguns conflitos que me cabe sanear de forma a evitar tensões no meu grupo de trabalho, assim como evitar que isso se reflicta na produtividade e na imagem da empresa. Para além disso e tendo em conta o facto de ter que lidar com os meus clientes, fornecedores e instituições do estado, mantenho uma postura cordata e tento sempre evitar situações de desentendimento de forma a facilitar a comunicação e potenciar os meus negócios. (Edmundo, 29 anos, empresário de empresa de equipamento elétrico)

O rol de competências descritas expressa, assim, um conjunto de qualidades que Dubar (2006) apelida de "vulgata da competência", uma espécie de "credo de administradores e consultores" e que inclui a iniciativa, a responsabilidade e o trabalho de equipe. A noção de carreira profissional é substituída pela noção de empregabilidade, sendo da responsabilidade de cada um a aquisição e manutenção das suas próprias competências: "eles são responsáveis pela sua competência, nos dois significados do termo: cabe-lhes a eles adquiri-las e são eles que sofrem se não as tiverem" (Dubar, 2006). As competências são descritas de forma indissociável do "eu", estão incorporadas nos indivíduos, sendo interiorizadas ao longo do percurso de vida e adquiridas nas formações e nas diferentes experiências profissionais. Desta forma, os percursos biográficos, e as aprendizagens que daí decorreram, assumem maior destaque que as pertenças a categorias profissionais e as descrições de conteúdos funcionais.

\section{Considerações Finais}

Da análise realizada ao conjunto de autobiografias que constituiu o corpus analítico desta investigação, concluiu-se que, na esfera profissional, a maior ou menor vinculação dos indivíduos a conteúdos funcionais estritos influencia o modo como estes se apresentam e caracterizam narrativamente. Com base nas categorias de análise definidas e da posterior classificação das narrativas autobiográficas nos modelos sistêmico-controlador e relacional-processual foi possível constatar que os valores em que ancoram o seu discurso autobiográfico é distinto, variando em função da incorporação de elementos do discurso de caracterização da organização e da gestão do trabalho que prevalece na sua experiência profissional. Os indivíduos imbricados no mundo social organizado e sólido da burocracia apresentam-se como protagonistas de um papel profissional que resulta de processos de socialização institucional. Por seu turno, os indivíduos com trajetórias profissionais mais próximas dos novos modelos de organização do trabalho apresentam uma implicação subjetiva mais débil, com prescrições normativas associadas a cargos profissionais e uma maior valorização discursiva de aspetos como a polivalência e a flexibilidade. 
A incorporação de referências distintas na sustentação da identidade profissional é o resultado da substituição de práticas fortemente reguladas, fundadas numa racionalidade positiva e universal, que supunha a obediência e a execução mecânica, por práticas de natureza mais participativa, autónoma, criativa e reflexiva. Não será excessivo considerar que a forma como os indivíduos atribuem sentido à sua experiência profissional influencia o seu comportamento organizacional. Os novos modelos da gestão empresarial orientam-se pelos princípios da criatividade, da reatividade e da flexibilidade, num claro contraponto aos princípios burocráticos que marcaram a gestão até à década de sessenta. O capitalismo legitima-se, recorrendo ao argumento da meritocracia, assente na justa retribuição em função da avaliação do desempenho individual, ao qual se acrescenta o argumento da liberdade, traduzido no convite ao desenvolvimento pessoal através do envolvimento do trabalhador na cultura organizacional.

Com efeito, os conceitos de autonomia e de liberdade passam a fazer parte do léxico das práticas de gestão e o desenvolvimento pessoal torna-se numa dimensão da nova gestão empresarial. Longe de permanecer vinculado a uma profissão ou a uma qualificação, a avaliação da grandeza do trabalhador faz-se com base, tanto na sua capacidade de adaptação, que lhe possibilite a transição e a maleabilidade a situações de diferente natureza, como na sua polivalência, que lhe permita a mudança de atividade ou de ferramentas, segundo a natureza da relação que estabelece com os outros ou com os objetos (Boltanski \& Chiapello, 2002). Os resultados obtidos nesta investigação revelam uma incorporação na narrativa autobiográfica destas alterações ocorridas na esfera laboral, revelando a sua permeabilidade aos modelos organizacionais que configuram a experiência profissional.

Nesse sentido, o trabalho gerencial deve tomar em consideração os processos de construção identitária dos diferentes agentes da organização, de modo a que, como afirma Watson (2005), o gestor assuma um papel ativo nos processos de construção social da realidade organizacional. Por sua vez, a orientação profissional deve tornar-se cada vez mais um processo participativo e cooperativo, favorecendo, como propõem Araújo, Paradiso, Lassance e Sarriera (2013), a participação ativa do cliente no processo de aconselhamento e na construção da sua carreira. O trabalho de orientação deve envolver a validação da noção individual de self e facilitar a sua integração nos diferentes contextos sociais. Este trabalho de organização das experiências de vida envolve a identificação e revisão dos seus significados. Como adianta Brott (2001), cabe ao orientador a co-construção, desconstrução e reconstrução das histórias narradas.

Os resultados obtidos são reveladores da forma como a lógica organizacional se reflete na identidade profissional dos indivíduos. Apesar da heterogeneidade das trajetórias profissionais e da singularidade das narrativas do ponto de vista subjetivo do narrador encontramos no discurso autobiográfico regularidades e padrões que revelam a influência do contexto social na identidade profissional. Evidencia-se nos resultados apresentados a relação entre os indivíduos e os contextos em que se inserem revelando a forma como ressoa no relato individual das micronarrativas o discurso socialmente legitimado das macro narrativas da gestão empresarial. Esse ponto de contacto entre o individual e o social, que constitui o eixo analítico dos relatos autobiográficos, é a pedra de toque de algumas das mais recentes abordagens teóricas no campo da orientação profissional (Savickas, 2012; LaPointe, 2010). Nos relatos analisados constatámos que o discurso narrativo da experiencia profissional constitui uma manifestação singular das influências sociais e da vulnerabilidade dos indivíduos às circunstâncias dos contextos em que se inserem.

O presente artigo objetiva contribuir para a demonstração das potencialidades da utilização da narrativa autobiográfica na área da orientação profissional, realçando a forma como o processo de construção identitária se desenvolve profundamente influenciado pela incorporação do discurso organizacional. A incorporação de referências que sustentam diferentes modos e lógicas de organização do trabalho traduz-se em formas distintas de entendimento da realidade que se reproduzem nas narrativas autobiográficas. Deve, no entanto, salientar-se que as narrativas autobiográficas utilizadas nesta investigação não foram produzidas em contexto de orientação profissional, podendo constituir, por isso, uma limitação. Os relatos em que se baseiam as conclusões resultam de contextos de maior liberdade narrativa na produção do sentido dos acontecimentos de vida quando comparados com os contextos da orientação profissional. Dessa forma, e apesar de ter sido possível evidenciar as estruturas sobre as quais os indivíduos descrevem, na narrativa autobiográfica, o seu self profissional, os modos de que se reveste a produção dessa narrativa no contexto particular da orientação profissional exigirão um maior aprofundamento que não cabe nos objetivos deste artigo.

\section{Referências}

Abrantes, P. (2013). A escola da vida: socialização e biografia(s) da classe trabalhadora. Lisboa: Mundos Sociais. 
Almeida, M., Candeias, P., Morais, E., Milagre, C., \& Lopes, G. (2008). Metodologia de acolhimento, diagnóstico e encaminhamento de adultos - Centros Novas Oportunidades. Lisboa: Agência Nacional para a Qualificação.

Ambiel, R. A. (2014). Adaptabilidade de carreira: uma abordagem histórica de conceitos, modelos e teorias. Revista Brasileira de Orientação Profissional, 15(1), 15-24. Recuperado em 21 de outubro 2017, de http://pepsic.bvsalud. org/pdf/rbop/v15n1/04.pdf

Araújo, G., Paradiso, Â., Lassance, M., \& Sarriera, J. (2013). Carreira e narrativa: contribuições para a intervenção. Revista Brasileira de Orientação Profissional, 14(2), 191-201. Recuperado em 21 de outubro 2017, de http://pepsic. bvsalud.org/pdf/rbop/v14n2/05.pdf

Bardin, L. (2009). Análise de conteúdo. Lisboa: Edições 70.

Bauman, Z. (1998). Modernidade e Holocausto. Rio de Janeiro: Jorge Zahar Ed.

Boltanski, L., \& Chiapello, È. (2002). El nuevo espíritu del capitalismo, Madrid: Akal.

Brott, P. E. (2001). The storied approach: A postmodern perspective for career counseling. The Career Development Quarterly, 49(4), 304-313. DOI: 10.1002/j.2161-0045.2001.tb00958.x

Bruner, J. (2003). Self-making narratives. In R. Fivush, \& C. A. Haden (Eds.), Autobiographical memory and the construction of a narrative self: Developmental and cultural perspectives. (pp. 209-226). Mahwah, NJ: Lawrence Erlbaum.

Dionísio, M., Castro, R., \& Silva, A. (2013). A relação com o escrito nos kits de identidade de adultos em processos de reconhecimento e certificação de competências. Scripta, 17(32), pp. 155-172. DOI: $10.5752 / \mathrm{P} .2358-3428.2013 \mathrm{~V} 17 \mathrm{~N} 32 \mathrm{P} 155$

du Gay, P. (2005). The values of bureaucracy. Oxford: Oxford University Press.

Dubar, C. (2001). La construction sociale de l'insertion professionnelle. Education et sociétés, (1), 23-36. DOI: 10.3917/ es.007.0023

Dubar, C. (2006). A crise das identidades: a interpretação de uma mutação. Porto: Edições Afrontamento.

Forrier, A., Sels, L., \& Stynen, D. (2009). Career mobility at the intersection between agent and structure: A conceptual model. Journal of Occupational and Organizational Psychology, 82(4), 739-759. DOI: 10.1348/096317909X470933

Guerra, I. (2008). Pesquisa qualitativa e análise de conteúdo: sentidos e formas de uso. Lisboa: Principia.

Ghiglione, R., \& Matalon, B. (2001). O inquérito. Lisboa: Celta Editora.

Kovács, I. (2006). Novas formas de organização do trabalho e autonomia no trabalho. Sociologia, problemas e práticas, $52,41-65$.

LaPointe, K. (2010). Narrating career, positioning identity: Career identity as a narrative practice. Journal of Vocational Behavior, 77(1), 1-9. DOI: https://doi.org/10.1016/j.jvb.2010.04.003

Lima, P., \& Coimbra, J. L. (2004). Narrativas de investimento vocacional contributo para a revisão das práticas de orientação vocacional no contexto escolar. In A. Sanchez \& M. Fernández. Necesidades de formación e deseño curricular por competencias: actas do V congreso internacional de Galicia e Norte de Portugal de formación para o traballo. (pp. 191-201). Santiago de Compostela: Universidade de Santiago de Compostela.

Macedo, L., \& Silveira, A. (2012). Self: A concept in development. Paidéia, 22(52), 281-290. DOI: https://dx.doi. org/10.1590/S0103-863X2012000200014

Meijers, F., \& Lengelle, R. (2012). Narratives at work: The development of career identity. British Journal of Guidance \& Counselling, 40(2), 157-176. DOI: 10.1080/03069885.2012.665159

Ribeiro, M. A. (2013). Sistematização das principais narrativas produzidas sobre carreira na literatura especializada. Revista Brasileira de Orientação Profissional, 14(2), 177-189. Recuperado em 21 de outubro 2017, de http://pepsic. bvsalud.org/pdf/rbop/v14n2/04.pdf

Ruquoy, D. (1997). Situação de entrevista e estratégia do entrevistador. In AA.VV., Práticas e métodos de investigação em ciências sociais, Lisboa, Gradiva.

Savickas, M. L. (2004). Um modelo para avaliação de carreira. In L. Leitão (Ed.), Avaliação Psicológica em orientação escolar e profissional. (pp. 21-44). Coimbra: Quarteto.

Savickas, M. (2005). The theory and practice of career construction. In S. D. Brown, \& R. W. Lent (Eds.), Career development and counseling: Putting theory and research to work. (pp. 42-70). Hoboken, NJ: John Wiley \& Sons.

Savickas, M. L. (2012). Life design: A paradigm for career intervention in the 21 st century. Journal of Counseling \& Development, 90(1), 13-19. DOI: 10.1111/j.1556-6676.2012.00002.x

Silva, A., Taveira, M., \& Ribeiro, E. (2011). Self de carreira: estudo longitudinal com estudantes universitários. Psicologia: Teoria e Pesquisa, 27(3), 263-272. DOI: https://dx.doi.org/10.1590/S0102-37722011000300001 
Stebleton, M. (2010). Narrative-based career counseling perspectives in times of change: An analysis of strengths and limitations. Journal of Employment Counseling, 47(2), 64-78. DOI: DOI: 10.1002/j.2161-1920.2010.tb00091.x

Watson, T. (2005). Organização e trabalho em transição: da lógica "sistêmico-controladora" à lógica "processualrelacional". RAE-Revista de Administração de Empresas, 45(1), 14-23. DOI: http://dx.doi.org/10.1590/ S0034-75902005000100003

Watson, T. (2008). Managing identity: Identity work, personal predicaments and structural circumstances. Organization, 15(1), 121-143. DOI: https://doi.org/10.1177/1350508407084488

Recebido: $17 / 05 / 2015$

$1^{a}$ reformulação: 09/10/2015

$2^{a}$ reformulação: 03/08/2016

$3^{a}$ reformulação: 09/04/2017

Aceite final: 21/07/2017

Sobre o autor

António Calha é Professor Adjunto do Instituto Politécnico de Portalegre. Licenciado em Sociologia pela Faculdade de Economia da Universidade de Coimbra, Mestre em Sociologia pela Universidade de Évora e Doutor em Sociologia pelo Instituto de Ciências Sociais da Universidade de Lisboa. 